\section{Screening for age- related macular degeneration using nonstereo digital fundus photographs}

\begin{abstract}
Age-related macular degeneration (AMD) is a disease with significant visual morbidity and accounts for the majority of blind registrations in the developed world including the UK. Certain forms of neovascular AMD are amenable to treatment but require expeditious referral to a retinal specialist.

Aim To evaluate the possibility of using nonstereo fundus photographs as a low-cost screening tool for neovascular
\end{abstract} AMD.

Design Retrospective review of patients referred to the macular clinic of a teaching hospital in London.

Methods A total of 198 randomised digital fundus photographs, without any other clinical information, were presented to two independent ophthalmic interns who graded them into one of the three categories: normal, age-related maculopathy (ARM), or neovascular age-related macular degeneration (AMD) to determine the urgency of referral to clinic. The results were compared with the known diagnosis for each patient and sensitivities and specificities for each diagnostic category calculated.

Results The intraobserver Kappa statistic was 0.75 and 0.91 for grader 1 and 2, respectively. The interobserver Kappa was 0.54 . The mean sensitivity and specificity for the identification of ARM was 60.5 and $76.3 \%$, respectively The mean sensitivity and specificity for the identification of AMD was 85.7 and $78.8 \%$, respectively.

Conclusion Nonstereo digital fundus photograph is a reasonable screening tool for $\mathrm{CNV}$ and may aid in decreasing the visual morbidity it causes by enabling timely referrals and treatment.

Eye (2006) 20, 471-475. doi:10.1038/sj.eye.6701916; published online 13 May 2005

S Jain, S Hamada, WL Membrey and V Chong

Keywords: AMD; CNV; screening; digital; PDT

\section{Introduction}

Age-related macular degeneration (AMD) is the most common cause of blind registration in the majority of the developed world today including the United Kingdom. ${ }^{1-3}$ According to current estimates there are around 172000 people with geographic AMD in the UK and 245000 with neovascular AMD. ${ }^{4}$ It is thus a condition, which causes significant visual morbidity.

There is still considerable variability in terminology of age-related macular disease. Most medical retinal specialists segregate it into age-related maculopathy (ARM) and AMD. The former can be early with drusen and/or mild RPE abnormalities or late with features of geographic atrophy. AMD is usually neovascular in nature with features of choroidal neovascularisation (CNV), pigment epithelial detachment (PED) etc. ${ }^{5}$

Since vision loss usually accompanies the late complications of ARM, some still refer to this as AMD. Atrophic ARM leads to gradual loss of vision, which is usually not as severe as neovascular AMD that can cause extensive loss of central visual acuity relatively rapidly. Until recently there was no treatment for subfoveal $\mathrm{CNV}$ that did not produce immediate, severe loss of vision as a side effect.

However, with recent advances new techniques have emerged that can stabilise or retard the deterioration in vision in selected cases of neovascular AMD. The most effective treatment techniques include photodynamic therapy (PDT) $)^{6-9}$ and transpupillary thermotherapy (TTT) ${ }^{10-12}$ that use laser to ablate the neovascular membrane. However, they have
Retinal Research Unit, Kings College Hospital, Denmark Hill, London, UK

Correspondence: S Jain, Department of Ophthalmology, Leicester Royal Infirmary, Leicester LE1 5 WW, UK Tel: +441162541414 Fax: + 441162586965 E-mail: drsaurabhjain@ hotmail.com

Received: 14 December 2004

Accepted in revised form: 21 March 2005 Published online: 13 May 2005

We certify that this work has not been submitted or been previously published in any other journal. No grants or sponsorships have been requisitioned for this study. The authors do not have any commercial interest in any product or procedure mentioned in this manuscript. This work has been presented at the annual meeting of the Association for research in vision and ophthalmology (ARVO) 25-29 ${ }^{\text {th }}$ April 2004 Ft Lauderdale. 
a narrow window of opportunity to treat for maximum therapeutic benefit.

The rationale of screening for neovascular AMD is the assumption that facilitating access to treatment earlier in the disease could well-improve therapeutic outcomes. If eligible patients were identified before severe loss of vision, smaller and potentially less active lesions could be treated more frequently, resulting in more successful treatments as a whole.

Telescreening for AMD is still in its infancy compared to that for diabetic retinopathy probably because early signs like patchy atrophy and small drusens are more difficult to detect and grade than microaneurysms and haemorrhages. ${ }^{13}$

Previous studies have utilised $35 \mathrm{~mm}$ colour film photographs or digitised images thereof to screen the target population for choroidal neovascularisation. ${ }^{14-16}$ However, to the best of our knowledge there have been no studies on the effectiveness of primary digitally captured images for AMD screening.

The aim of this study was to investigate the reliability of nonstereoscopic digital photographic screening for neovascular AMD.

\section{Materials and methods}

All digital images were selected from the photographic database of the medical retina department at King's College Hospital. This database resulted from the routine clinical care of patients seen in the department. The local ethical committee was consulted and approval obtained. Mydriasis was performed using 1\% Tropicamide and 2.5\% Phenylepherine. Digital colour fundus images were then captured using the Topcon TRC-50EX fundus camera (Topcon Corporation, Tokyo, Japan).

The subset of 198 images used in this study was selected by a medical retinal specialist (VC). This included macular images of the following: normals (66), ARM (57), as well as neovascular AMD (56). Another 19 images were duplicated and represented in random order with the other images in order to assess intraobserver agreement. Normal fundus images were drawn from fellow eyes of patients with uniocular disease including retinal vascular occlusions. Only one eye of each patient was selected to be included in the study.

The images were processed and presented to two independent ophthalmic interns (SJ and $\mathrm{SH}$ ) in random order using the Imagenet system. No information regarding the age, sex, visual acuity, or clinical history of the patients in the study group was given to the graders. The images were viewed on a Dell computer monitor set at 32 bits true colour with a $1280 \times 1024$ pixel resolution.

The observers were instructed to grade the images into one of the three categories Normal, ARM (early or late) and AMD (including CNV and PED).

Normals had none or minimal changes of age-related disease at the macula. The ARM group included patients with drusens, hard exudates and retinal pigment epithelial (RPE) changes including geographic atrophy. The AMD group included patients with features of CNV, subretinal haemorrhage, PED, and subretinal fluid.

The two grader's interobserver and intraobserver agreement on the category the patient would be placed in was assessed using the kappa statistic. The results were compared with the known category for each patient decided by the medical retina specialist (VC) based on the clinical history, examination findings and investigations. The sensitivities and specificities for each diagnostic category were calculated.

All analyses were carried out using the Statistical Package for the Social Sciences SPSS 8.0.0. (SPSS Inc., Chicago, IL, USA).

\section{Results}

The agreement between the two graders and the true category classification is depicted in Tables 1 and 2. The

Table 1 True classification $(\mathrm{TC}) \times$ grader 1 classification cross tabulation

\begin{tabular}{|c|c|c|c|c|c|c|}
\hline & & & \multicolumn{3}{|c|}{ Grader 1} & \multirow[t]{2}{*}{ Total } \\
\hline & & & Normal & $A R M$ & $A M D$ & \\
\hline \multirow{6}{*}{ True classification (TC) } & Normal & Count & 58 & 7 & 1 & 66 \\
\hline & & $\%$ within TC & 87.9 & 10.6 & 1.5 & 100.0 \\
\hline & ARM & Count & 4 & 29 & 24 & 57 \\
\hline & & $\%$ within TC & 7.0 & 50.9 & 42.1 & 100.0 \\
\hline & AMD & Count & 4 & 6 & 46 & 56 \\
\hline & & $\%$ within TC & 7.1 & 10.7 & 82.1 & 100.0 \\
\hline \multirow[t]{2}{*}{ Total } & & Count & 66 & 42 & 71 & 179 \\
\hline & & $\%$ within TC & 36.9 & 23.5 & 39.7 & 100.0 \\
\hline
\end{tabular}


Table 2 True classification $(\mathrm{TC}) \times$ grader 2 classification cross tabulation

\begin{tabular}{|c|c|c|c|c|c|c|}
\hline & & & \multicolumn{3}{|c|}{ Grader 2} & \multirow[t]{2}{*}{ Total } \\
\hline & & & Normal & ARM & $A M D$ & \\
\hline \multirow[t]{6}{*}{ True classification (TC) } & Normal & Count & 32 & 24 & 10 & 66 \\
\hline & & $\%$ within TC & 48.5 & 36.4 & 15.2 & 100.0 \\
\hline & ARM & Count & & 40 & 17 & 57 \\
\hline & & $\%$ within TC & & 70.2 & 29.8 & 100.0 \\
\hline & AMD & Count & & 6 & 50 & 56 \\
\hline & & $\%$ within TC & & 10.7 & 89.3 & 100.0 \\
\hline \multirow[t]{2}{*}{ Total } & & Count & 32 & 70 & 77 & 179 \\
\hline & & $\%$ within TC & 17.9 & 39.1 & 43.0 & 100.0 \\
\hline
\end{tabular}

Table 3 Grader $1 \times$ grader 2 classification crosstabulation (interobserver variability)

\begin{tabular}{|c|c|c|c|c|c|c|}
\hline & & & \multicolumn{3}{|c|}{ Grader 2} & \multirow[t]{2}{*}{ Total } \\
\hline & & & Normal & $A R M$ & $A M D$ & \\
\hline \multirow[t]{6}{*}{ Grader 1} & Normal & Count & 31 & 21 & 14 & 66 \\
\hline & & $\%$ within grader 1 & 47.0 & 31.8 & 21.2 & 100.0 \\
\hline & ARM & Count & & 36 & 6 & 42 \\
\hline & & $\%$ within grader 1 & & 85.7 & 14.3 & 100.0 \\
\hline & AMD & Count & 1 & 13 & 57 & 71 \\
\hline & & $\%$ within grader 1 & 1.4 & 18.3 & 80.3 & 100.0 \\
\hline \multirow[t]{2}{*}{ Total } & & Count & 32 & 70 & 77 & 179 \\
\hline & & $\%$ within grader 1 & 17.9 & 39.1 & 43.0 & 100.0 \\
\hline
\end{tabular}

Table 4 Subjective $1 \times$ subjective 2 crosstabulation (grader 1 ) intraobserver variability

\begin{tabular}{|c|c|c|c|c|c|c|}
\hline & & & \multicolumn{3}{|c|}{ Subjective 2} & \multirow[t]{2}{*}{ Total } \\
\hline & & & Normal & $A R M$ & $A M D$ & \\
\hline \multirow[t]{6}{*}{ Subjective 1(Subj1) } & Normal & Count & 5 & 2 & & 7 \\
\hline & & $\%$ within Subj1 & 71.4 & 28.6 & & 100.0 \\
\hline & ARM & Count & & 2 & 1 & 3 \\
\hline & & $\%$ within Subj1 & & 66.7 & 33.3 & 100.0 \\
\hline & AMD & Count & & & 9 & 9 \\
\hline & & $\%$ within Subj1 & & & 100.0 & 100.0 \\
\hline \multirow[t]{2}{*}{ Total } & & Count & 5 & 4 & 10 & 19 \\
\hline & & $\%$ within Subj1 & 26.3 & 21.1 & 52.6 & 100.0 \\
\hline
\end{tabular}

agreement between the two graders (interobserver variability) is shown in Table 3. The interobserver Kappa was 0.54 , primarily due to disagreement over 'normals'.

The cross tabulation and calculation of the intraobserver variability using the duplicated images (Tables 4 and 5) gave a Kappa statistic of 0.75 and 0.91 for grader 1 and 2, respectively.

The mean sensitivity and specificity for the identification of ARM was 60.5 and $76.3 \%$, respectively.
The mean sensitivity and specificity for the identification of AMD was better at 85.7 and $78.8 \%$, respectively (Table 6).

\section{Discussion}

Screening of retinal pathology using fundal photographs has been extensively used for conditions like diabetic 
Table 5 Subjective $1 \times$ subjective 2 crosstabulation (grader 2 ) intraobserver variability

\begin{tabular}{|c|c|c|c|c|c|c|}
\hline & & & \multicolumn{3}{|c|}{ Subjective 2} & \multirow[t]{2}{*}{ Total } \\
\hline & & & Normal & $A R M$ & $A M D$ & \\
\hline \multirow[t]{6}{*}{ Subjective 1 (Subj1) } & Normal & Count & 2 & 1 & & 3 \\
\hline & & $\%$ within Subj1 & 66.7 & 33.3 & & 100.0 \\
\hline & ARM & Count & & 5 & & 5 \\
\hline & & $\%$ within Subj1 & & 100.0 & & 100.0 \\
\hline & AMD & Count & & & 11 & 11 \\
\hline & & $\%$ within Subj1 & & & 100.0 & 100.0 \\
\hline \multirow[t]{2}{*}{ Total } & & Count & 2 & 6 & 11 & 19 \\
\hline & & $\%$ within Subj1 & 10.5 & 31.6 & 57.9 & 100.0 \\
\hline
\end{tabular}

Table 6 Sensitivity and specificity of detection of ARM and AMD

\begin{tabular}{|c|c|c|c|c|c|c|}
\hline & \multicolumn{2}{|c|}{ Grader 1} & \multicolumn{2}{|c|}{ Grader 2} & \multicolumn{2}{|c|}{ Mean } \\
\hline & $A R M(\%)$ & $A M D(\%)$ & $A R M(\%)$ & $A M D(\%)$ & $A R M(\%)$ & $A M D(\%)$ \\
\hline Sensitivity & 50.88 & 82.14 & 70.17 & 89.28 & 60.53 & 85.71 \\
\hline Specificity & 89.34 & 79.67 & 63.30 & 78.0 & 76.32 & 78.84 \\
\hline
\end{tabular}

retinopathy where the fundus photographs can be obtained by a trained technician at the GP surgery or designated centres and the images sent to the tertiary referral centre for grading. ${ }^{17}$ The previous gold standard for retinal photographic screening techniques has been film-based fundus images. According to the Wisconsin ARM grading system these have to include the central 30-35 degrees centred on the fovea and are usually presented as stereoscopic colour transparencies to the graders. ${ }^{18}$

However, with improvement in technology there has been a recent surge in interest in the use of highresolution digital imaging as a screening tool. Digital imaging has many inherent advantages over conventional film-based screening methods. ${ }^{17}$ It enables the photographer to instantly judge the quality of image capture and repeat it if necessary. The time, cost and inconvenience of mounting the slides is reduced and it is possible to transmit the images in a compressed format over long distances via electronic mail. ${ }^{18}$ Hence, experts at a referral centre can grade them easily and quickly without the need for patient contact and an appropriates clinic appointments can then be arranged. Digital imaging systems also allow for image magnification, contrast enhancement and use of various filters to facilitate grading. These reasons make it a viable and attractive option to film-based screening in the future.

In spite of its wide spread prevalence, screening for AMD in the past has not been a fruitful exercise due to lack of treatment options and inability to intervene in the disease progression. With advancement in laser techniques and pharmacological adjuncts, it is now possible to delay or even halt the progression of the disease in certain cases. ${ }^{6-12}$

The most popular among these is photodynamic therapy (PDT), which utilises the dye verteporfin to sensitise the retinal cells to the effect of laser energy. The neovascular membrane is then obliterated with much lower energy levels than would otherwise be required. ${ }^{6-9}$

However, it is crucial that the patient be referred to the treating physician at the earliest for the maximum benefit. The constraints of resources and infrastructure may however, lead to a significant delay between initial presentation to an eye care provider and obtaining a retinal opinion. A recent study found that $16 \%$ of patients were seen by retinal specialists $>6$ months after onset of visual symptoms. ${ }^{19}$

Clearly there is a need for a tool that will reduce this delay to enable prompt treatment of the selective but sizeable proportion of patients eligible for PDT. Investigators have looked into the possibility of using a screening service for AMD with consistently favourable reports. These have used variously film-based fundal images, using both stereoscopic and nonstereoscopic methods. ${ }^{13-15}$

Scholl et al sought to establish the reliability of digital nonstereoscopic images for grading of ARM. They reported that there was close agreement between digitised nonstereoscopic images and stereoscopic colour slides. ${ }^{15}$ However, we have not come across any study that has evaluated the ability of digital fundal photography to screen for ARM. 
We chose ophthalmic interns as graders, equating their ability to that of a photographic screener. The calculations for sensitivity levels comparing the graders to the specialist were very good, so the graders correctly identified most cases with neovascular AMD. We have discovered a good correlation between observer grading and clinical outcome in our study. Most false negatives were those with small classic CNV which are difficult to identify using nonstereo images alone as there might be no secondary clues, for example, exudates and haemorrhage; however, the elevation is more likely to be seen with stereo images.

We feel nonstereo screening techniques, while not as good as stereo photograph, can be easily implemented in GP practices, and offer the potential benefit of setting up a direct telemedicine link to the local hospital.

Hence, we feel that a nonstereo digital fundus photograph is a reasonable screening tool for CNV and may aid in decreasing the visual morbidity it causes by enabling timely referrals and treatment.

\section{References}

1 Arnold JJ, Sarks SH. Extracts from 'clinical evidence': age related macular degeneration. BMJ 2000; 321(7263): 741-744.

2 Bressler SB, Bressler NM, Fine SL. Age-related macular degeneration. Surv Ophthalmol 1988; 32: 375-413.

3 Klein R, Klein BEK, Linton KLP. Prevalence of age-related maculopathy: the Beaver Dam eye study. Ophthalmology 1992; 99: 933-943.

4 Owen CG, Fletcher AE, Donoghue M, Rudnicka AR. How big is the burden of visual loss caused by age related macular degeneration in the United Kingdom? $\mathrm{Br} \mathrm{J}$ Ophthalmol 2003; 87(3): 312-317.

5 Bird AC, Bressler NM, Bressler SB, Chisholm IH, Coscas G, Davis MD et al. An international classification and grading system for age-related maculopathy and age-related macular degeneration. The International ARM Epidemiological Study Group. Surv Ophthalmol 1995; 39(5): 367-374.

6 Treatment of Age-Related Macular Degeneration with Photodynamic Therapy (TAP) Study Group. Photodynamic therapy of subfoveal choroidal neovascularization in agerelated macular degeneration with verteporfin: one-year results of 2 randomized clinical trials-TAP report 1. Arch Ophthalmol 1999; 117: 1329-1345.
7 Verteporfin in Photodynamic Therapy (VIP) Study Group. Verteporfin therapy of subfoveal choroidal neovascularization in age-related macular degeneration: 2-year results of a randomized clinical trial including lesions with occult with no classic choroidal neovascularization - VIP Report 2. Am J Ophthalmol 2001; 131: 541-560.

8 Sternberg Jr P, Lewis H. Photodynamic therapy for age related macular degeneration. Am J Ophthalmol 2004; 137(3): 483-485.

9 Verteporfin Roundtable Participants. Guidelines for using verteporfin (Visudyne) in photodynamic therapy for choroidal neovascularization due to age-related macular degeneration and other causes: update. Retina 2005; 25(2): 119-134.

10 Newsom RSB, McAlister JC, Saeed M, McHugh JDA. Transpupillary thermotherapy (TTT) for the treatment of choroidal neovascularisation. Br J Ophthalmol 2001; 85: 173-178.

11 Ulbig M, McHugh J, Hamilton P. Photocoagulation of choroidal neovascular membranes with a diode laser. $\mathrm{Br}$ Ophthalmol 1993; 77: 218-221.

12 Reichel E, Puliafito CA, Duker JS, Guyer DR. Indocyanine green dye-enhanced diode laser photocoagulation of poorly defined subfoveal choroidal neovascularization. Ophthalmic Surg 1994; 25(3): 195-201.

13 van Leeuwen R, Chakravarthy U, Vingerling JR, Brussee C, Hooghart AJ, Mulder PG et al. Grading of age-related maculopathy for epidemiological studies: is digital imaging as good as 35-mm film? Ophthalmology 2003; 110(8): $1540-1544$.

14 Maberley DAL, Isbister C, MacKezie P, Aralar A. An evaluation of photographic screening for neovascular age-related macular degeneration. Eye advance online publication, 28 May 2004, doi:10.1038/sj.eye.6701584.

15 Scholl HP, Dandekar SS, Peto T, Bunce C, Xing W, Jenkins S et al. What is lost by digitizing stereoscopic fundus color slides for macular grading in age-related maculopathy and degeneration? Ophthalmology 2004; 111(1): 125-132.

16 Liesenfeld B, Kohner E, Piehlmeier W, Kluthe S, Aldington $\mathrm{S}$, Porta $\mathrm{M}$ et al. A telemedical approach to the screening of diabetic retinopathy: digital fundus photography. Diabetes Care 2000; 23(3): 345-348.

17 Williamson TH, Keating D. Telemedicine and computers in diabetic retinopathy screening. Br J Ophthalmol 1998; 82(1): 5-6.

18 Ryder RE. Screening for diabetic retinopathy in the 21st century. Diabet Med 1998; 15(9): 721-722.

19 Haddad WM, Seres A, Coscas G, Soubrane G. Presentation delay in patients affected with age -related macular degeneration. Graefe's Arch Clin Exp Ophthlamol 2002; 240(1): $31-34$. 